\title{
Como gallo en la raya. Comunicación, género y cultura
}

\author{
María Eugenia Suárez de Garay \\ CEG-UDEG
}

\begin{abstract}
Este trabajo está centrado en el rescate de la palabra como el elemento que permite la simbolización y elaboración de las manifestaciones sobre el ser femenino.
\end{abstract}

$\mathrm{H}$

oy hablaré de un trabajo que concluí hace algunos meses, el cual me hizo reflexionar sobre lo que ha significado la experiencia de acercarme al mundo de la oralidad, ese mundo que se transforma en la escritura de elementos vocales simbólicos, que simultáneamente nos muestra el horizonte de posibilidades latentes y de las limitaciones que nos impone la propia libertad condicional.

Mi trabajo de tesis, que lleva por título "Como gallo en la raya. Comunicación, género y cultura. Un análisis de caso", ha conjugado, por un lado, mi preocupación por abordar desde una particular perspectiva de género la construcción de la feminidad -proceso que se da esencialmente en nuestras prácticas comunicativas y culturales, y espacio idóneo para el juego de las representaciones y significación de la realidad-, y, por otro lado, la preocupación por construir el camino hacia el encuentro y conocimiento de este proceso, utilizando específicamente la historia de vida. Así, creo que el aporte fundamental de este trabajo se centra en el rescate de la palabra como elemento que permite la simbolización y elaboración de las manifestaciones 
sobre el ser femenino; la palabra que adquirió una eficacia simbólica, la palabra libre y evidenciada, la palabra que no tuvo posibilidades de ser pronunciada, la que silenciosamente se ocultaba en el cuerpo y que sólo tiene posibilidades de surgir a partir del mismo.

Nunca pretendí hablar de una generalidad, sino centrarme en un solo caso y desentrañar un proceso que ocurre en forma sutil, que por sí solo habla de un mundo social que es compartido, recordado, escuchado y vivido en múltiples tiempos y con distintos rostros. Así que decidí trabajar con una sola sujeto. ¿Pero por qué con una sola mujer? En principio porque me parecía vital ser coherente con mi deseo. Quería trabajar seria y profundamente con la memoria, ese dispositivo generador y reconstructor del pasado, de lo vivido, de lo que se está viviendo y de las imágenes del futuro. El haber utilizado para ello la historia de vida, que tiene su sentido completo en la oralidad que es su territorio, permitió interpretar las expresiones de la experiencia de habitar un cuerpo de mujer. Profundizar en esta complicada versión individual y colectiva de nuestra sociedad y su época, constituye hoy por hoy uno de los objetos de investigación a mi parecer más sugestivos que se ofrecen a la curiosidad de los estudiosos y estudiosas del género.

En este sentido, esta perspectiva teórica, me refiero a la compresión de género como concepto,

se ha vuelto imprescindible, no sólo porque se propone explorar uno de los problemas intelectuales y humanos más intrigantes - ¿cuál es la verdadera diferencia entre los cuerpos sexuados y los seres socialmente construidos?-, sino también $[\ldots]$ porque pone en cuestión la idea de lo natural - tan vinculada con la de lo divino- y señala que es la simbolización cultural, y no la biología, la que establece las prescripciones relativas a lo que es propio de cada sexo. ${ }^{1}$

Así, este mandato cultural, esta normatividad genérica, no solamente se mueve en un nivel simbólico, sino que también se manifiesta en acciones concretas: moldea nuestra percepción de la vida en general y en particular, pone en evidencia la valoración, el uso y las atribuciones diferenciadas que se da a los cuerpos de las mujeres y de los hombres; se reproduce en la vida cotidiana, en el quehacer de todos los días, en las relaciones sociales, en los comportamientos individuales y en los distintos espacios sociales en los que se desenvuelven los sujetos. Así pues, entendemos que lo que define al género es la acción simbólica colectiva. Mediante la constitución del orden simbólico en una sociedad, se fabrican las ideas de lo que deben ser los hombres y las mujeres. Esto implica una constante división de la vida en esferas masculinas y femeninas, que es esencialmente cultural.

Las diferencias sustanciales surgidas a partir del género no implican solamente diferencias entre los valores y expectativas sociales caracterizadas como masculinas y femeninas, sino que conllevan, fundamentalmente, una diferencia de prestigio y ejercicio de poder entre ambos sexos. Los pro-

${ }^{1}$ Lamas, Género, 1996. 
cesos de socialización mediante los cuales se articulan relaciones mediatizadas por género se encargan de enseñar a los individuos a actuar y pensar dentro de las normas sociales que consideran a los sexos como opuestos, al mismo tiempo que asignan un mayor estatus al sexo masculino y empujan necesariamente a reconocer las jerarquías construidas. Estas formas culturales claro está que no son homogéneas, sino que se construyen de manera diferencial a partir también de otros elementos como clase, edad, ciclo de vida, escolaridad, etcétera.

La incorporación y adscripción de los sujetos a las instituciones sociales sabemos que constituyen fuentes privilegiadas para la elaboración y construcción de realidades particulares. En este proceso relacional se pretende asegurar una socialización mediante la cual se ofrecen pautas de comportamiento, valores y normas que adquieren carácter de justificación y sanción. Es decir, se fabrican las ideas del ser y deber ser para hombres y mujeres. Sin embargo, los significados no son estáticos ni singulares. Los significados son inestables, múltiples, cambiantes y siempre están siendo renegociados y regenerados por la comunicación y la acción. "Aun en el entendido de que ellos se producen básicamente en la desigualdad."2 En este sentido, la comunicación es un elemento central en la construcción del género. No es sino a partir de ella que es posible dar nombre y cuerpo a una sociedad que busca crear y disciplinar las imágenes de lo masculino y lo femenino.

${ }^{2}$ Hare y Marecek, Marcar, 1994, p. 15.
De ahí la importancia e interés por explorar e indagar los significados que dan los actores sociales a sus propias vivencias y prácticas derivadas de su identificación dentro de un cuerpo u otro. Una de las posibilidades para acceder a dichos significados es la memoria del sujeto, que mediante un proceso de autorreflexión y a través de prácticas discursivas permite construir las huellas de la modulación que las instituciones, desde sus discursos, agentes y prácticas, realizan a propósito de la identidad de género en la vida de un sujeto.

En este sentido, intenté profundizar específicamente en los universos simbólicos propuestos por la familia, la religión y la acción política a propósito de la feminidad: universos que adquieren especificidad en el sujeto, en la forma en que los representa y vive cotidianamente. Trabajar desde la memoria del sujeto nos introduce pues, en profundidad, en el universo de las relaciones sociales, las pautas de formación y funcionamiento de las redes de sociabilidad y el impacto de las transformaciones, su orden y su importancia en la vida cotidiana, no sólo del sujeto, sino de su grupo primario y el entorno social inmediato.

En el caso particular de este trabajo, el uso específico de la historia de vida -que busca adentrarse en la memoria de un sujeto y reconstruir su propio proceso como individuo-, se justifica fundamentalmente por el carácter exploratorio de esta tesis. Considerando la relativa novedad y muchas veces rechazo del análisis de género, desde la disciplina de la comunicación y, más concretamente, del intento de obser- 
var cómo ha vivido, cómo vive, qué experiencias significativas a través de las cuales la sujeto se constituye, era difícil partir de hipótesis preconstruidas. Siempre se parte de ciertos supuestos, pero precisamente la decisión de utilizar el método biográfico buscaba descubrir dimensiones capaces de guiar el transcurso de la investigación y de señalar nuevos caminos por los que se pudiera seguir explorando.

Como ya lo mencioné, decidí trabajar con una sola sujeto. La informante seleccionada reunía una serie de características importantes: pertenecía a una familia arraigada en el barrio de Analco desde hacía mucho tiempo, con un alto nivel de participación en el movimiento organizativo pero, sobre todo, con un cambio drástico en su vida tras las trágicas explosiones en el Sector Reforma de esta ciudad el 22 de abril de 1992. Es decir, de ser una mujer con una carga y práctica religiosa, con una participación en partidos políticos conservadores, con un proyecto de vida que tendía a la reproducción de ciertos papeles, pasa a ser una mujer líder, con capacidad de negociación, con reconocimiento en su barrio como dirigente y con seguridad para relacionarse con los medios de comunicación. Se da entonces un proceso de confrontación entre la identidad construida anteriormente a las explosiones y lo que este nuevo estado le va ofreciendo, donde se ponen en juego sus esquemas y modos de entender el mundo.

Sin embargo, para los fines del proyecto no bastaba con el solo ejercicio de rescatar la historia de vida de esta mujer y el conocimiento e información recabada durante la fase de ob- servación en la zona siniestrada. Era necesario tener otro tipo de panorama general que permitiera conocer de dónde provenía, cómo era la dinámica familiar en la que se había desarrollado y, sobre todo, qué tipo de ideología familiar, religiosa, educativa y política le daban cuerpo a esta sujeto. Así, cra importante realizar una historia de familia que permitiera conocer todos estos aspectos. Procedí a seleccionar a varios sujetos pertenecientes a la familia. Trabajé con el padre y la madre, ya que parto del supuesto de que son agentes determinantes en la socialización de la sujeto. Asimismo, decidí trabajar con una hermana, ya que me interesaba rescatar otra mirada del proceso de socialización que de alguna manera se podía asemejar y diferenciar de la narración que haría la sujeto.

Comencé el trabajo de campo en octubre de 1993, entrevistando a los tres miembros de la familia (madre, padre y hermana). El material generado en esta fase fueron: tres entrevistas a profundidad con miembros de la familia de la sujeto seleccionada y una historia de familia, donde se narra cómo han sido las trayectorias de los sujetos. La grabación de la historia de vida comenzó en noviembre de 1993 y terminó en febrero de 1994. Fueron aproximadamente quince sesiones, con un tiempo aproximado de dos horas y media cada una. Fue un ejercicio muy importante en mi formación como investigadora. Creo que aventurarse a este mundo de un sujeto, con su riqueza de detalle, su humanidad, su emoción frecuente, exigió muchísima concentración y respeto de ambas partes. De alguna manera mi ob- 


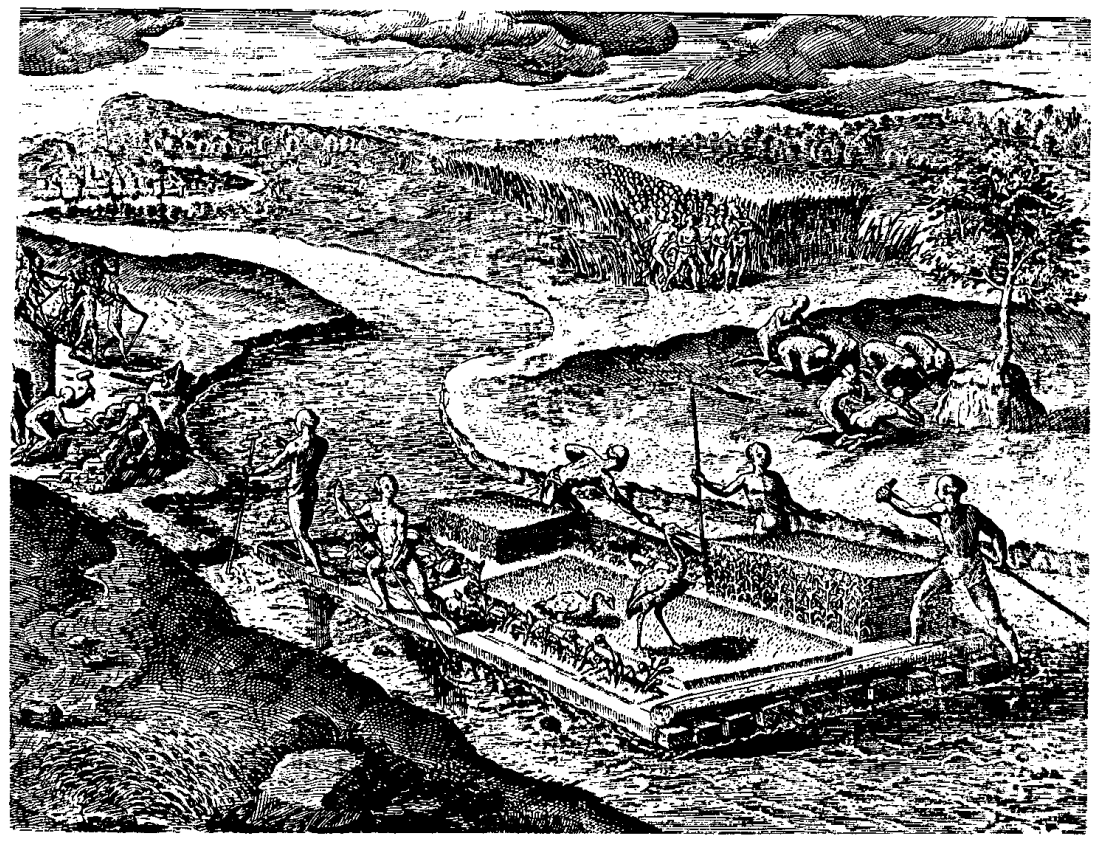

jeto de estudio se fue convirtiendo también en el objeto de la entrevistada: introducirnos y rascar en la memoria para poder armar las huellas de la historia. En mí pasaron muchas cosas: reafirmé mi pasión por el método; me recordé en los distintos momentos de mi vida; aprendí de la historia que escuché, y expuse mis propias limitaciones y miedos como investigadora. Y es que como dice Sidney Mintz, "en la historia de vida el etnógrafo y el informante se entrevistan mutuamente". ${ }^{3}$

${ }^{3}$ Mintz, "Anthropological", 1979, pp. 18-26, cit. por Morin, "Praxis", 1993, p. 96.
Cuando la información de la historia de vida estuvo transcrita, el primer paso fue su ordenación y clasificación. La sujeto abordó una multitud de representaciones sobre sí misma, sobre su relación con otros, sobre la vida y el mundo; estructuradas en familia, educación, medios de comunicación, barrio, relaciones sexuales, relaciones con los hombres, trabajo, salud, tiempo libre, mujeres, etc. A partir del 22 de abril aparecen otras, tales como: conflictos internos, desalojo, mujeres de apoyo, organización interna de damnificados, zona de desastre, autoridades, liderazgo, grupos de apoyo, for- 
mación política, conflictos barriales, etc. Como puede suponerse era prácticamente imposible abordar ese universo de significados. Lo anterior implicaba hacer un recorte que permitiera constituir ejes analíticos para mirar las mediatizaciones de género, reconocer las constantes, reconocer los ámbitos olvidados y entender cuáles eran aquellas instituciones que habían marcado a la sujeto de manera sobresaliente. Como ya lo mencioné, los ejes analíticos que seleccioné fueron familia, religión y acción política, porque representan las huellas más fuertes en la socialización de la sujeto. Sin embargo, esto no significa que no exis$\tan$ otras cuyas aportaciones sean semejantes en el transcurso de vida, pero era importante adentrarse en aquellos universos simbólicos por la trascendencia en la vida de la sujeto, entender su significado y el significado de la importancia que la sujeto le da y cómo influye en sus modos de relación. En este sentido, Bonnain y Elegoet señalan que "no se trata de hacer que el objeto encaje en categorías externas, sino por el contrario, de extraer las construcciones internas de la sociedad por medio de las propias categorias semánticas del informante".

Por otro lado, establecí una temporalidad analítica: introductoria, de ruptura y de conflicto. Estos tiempos analíticos se constituyen en tres etapas: la introductoria, que comprende desde las primeras etapas de vida hasta antes de las explosiones del 22 de abril; la de

\footnotetext{
"Bonnain, y Elegoet, "Mémoires", 1978, p. 3354 , cit. por Morin, "Praxis", 1993, p. 87.
}

ruptura, recupera el 22 de abril como una situación emergente que pone en juego las certezas sobre la realidad; la de conflicto, una nueva situación tras los acontecimientos que lleva necesariamente a una resignificación sobre lo aprendido y a la incorporación de nuevos elementos.

Así pues, determiné el cruce temporalidad analítica/eje analítico que constituyó uno de los elementos centrales para la intervención y edición de la historia de vida. El otro elemento es el género. Es decir, a partir del tiempo y del eje se fueron seleccionando aquellos aspectos que ponen en evidencia la incorporación de los sentidos de ser de la sujeto a partir de su pertenencia a determinado sexo y, por otro lado, permite observar rasgos que caracterizan el discurso de las instituciones y la acción y significación que los sujetos producen a partir de su pertenencia a las mismas.

A partir del recorrido realizado en el análisis, diría que no podemos dejar de reconocer la diversidad que existe entre las formas de ser mujer y de ser hombre. No obstante, aceptar la diversidad exige trazar caminos que permitan reconocer aquello que históricamente se ha asociado a hombres y mujeres y que tiene formas inéditas de expresarse. En este sentido, explorar las interrogantes acerca de aquellos elementos que constituyen la identidad genérica implica para el analista reconocer la tensión entre permanecer anclado en los papeles asignados o ir más allá de ellos; conflicto que pone de manifiesto que las formas sociales prescritas no se hallan intrínsecamente vinculadas con los rasgos de la mu- 
jer y el hombre," sino con un mundo simbólico que se estructura a partir del lenguaje y la comunicación, en las prácticas sociales, evocando cultura.

Ciertas ideas, perspectivas y acciones están históricamente asociadas con las mujeres o con los hombres, y tales asociaciones no son mera coincidencia sino un producto de experiencias culturales y sociales. En este sentido los tres universos simbólicos -familia, religión y acción política-, resultan fundamentales en la vida de la sujeto entrevistada, hablan de cómo la cultura proporciona significados a la experiencia humana y pone de manifiesto que no se es mujer por condición biológica; que el ser mujer, como el ser hombre, es producto del condicionamiento social.

Es sabido que para el bienestar físico, psicológico y social, los sujetos requieren de la integración en redes sociales. Redes que confieren identidad y sentido. Sin embargo, mediante el análisis de género ha sido posible deconstruir la definición tradicional de la familia que, para la identidad femenina, plantea el ser madre y esposa en exclusiva. Se han detectado las fisuras, contradicciones y ambigüedades que se producen en el ámbito familiar. Estas ambigüedades también son producto de las experiencias que la sujeto adquiere en su vivencia del tiempo, que es esencial. En las primeras etapas el discurso familiar convencional es asumido y vivido por la sujeto, pero ante los acontecimientos del 22 de abril, comienza a vivir una vida contradictoria y fragmentada en las diversas circunstancias cotidianas que ponen en juego y en tela de juicio lo aprendido.
Lo anterior indica que, en la actualidad, los vínculos y contenidos simbólicos que se establecen en la familia pueden ser rebasados por la incorporación de sus miembros a espacios alternativos de sociabilidad, a organizaciones alternativas o complementarias, poniendo en juego elementos que reestructuran las maneras de asumir y vivir el discurso familiar y todas las representaciones que sobre el yo, los otros y el contexto, se derivan del mismo.

En lo referente a la religión, se ha visto que la actuación tradicional asignada por ésa a las mujeres, las sume en un ámbito en el cual la voz casi siempre la tienen sus figuras oficiales (sacerdotes, padres, etc.). Aquí la familia juega también un papel importante porque refuerza las normas que prescribe la religión, a través del establecimiento de ciertos rituales y disciplinas. Así, la sujeto se enfrenta a sus características particulares -la menstruación, el cuerpo, el placer, la sexualidad- bajo el signo de lo misterioso, lo desconocido, lo pecaminoso, lo infranqueable. Este estado de cosas -a partir de las nuevas experiencias-, lleva a la necesidad de salir del silencio y enfrentar la propia existencia más allá de los estereotipos, y cuestionar lo que parece inmutable o eterno. Sin embargo, este recorrido de resignificaciones produce sentimientos siempre encontrados entre lo que se ha sido y lo que el presente propone como nuevas opciones de vida.

Los significados de lo sagrado, las imágenes de lo divino, su articulación con lo humano y la ritualización de esta interacción entre el ser supremo 
y las mujeres, dibuja un tejido social donde ellas juegan un papel importante; fundamentalmente se basa en una continua sucesión de expropiaciones, y entre todas, la del cuerpo tiene categoría relevante. ${ }^{5}$ El cuerpo marca las pautas y define la ubicación de la mujer en el mundo masculino, introduciendo con ello el elemento de la culpa y obstruyendo el encuentro de salidas auténticamente liberadoras de vida. Así pues, para la sujeto el proceso de recuperación del cuerpo ha representado una condición prioritaria para su desarrollo personal. De nueva cuenta, lo aprendido desde la religión y la familia se deconstruye para cobrar nuevos significados en el recorrido de autonombrar lo silenciado, lo oculto y lo vergonzoso. Es importante mencionar que, si bien estos procesos resultan estimulantes para la sujeto, nunca están exentos del conflicto que por sí mismos presentan.

El 22 de abril de 1992 ha representado en la memoria colectiva un hecho importante. Las expresiones de sus consecuencias, en la voz de múltiples actores sociales en la ciudad de Guadalajara, se hicieron oír. Los afectados por las explosiones guardan una historia que difícilmente se olvida, y ello también se manifiesta de distintas maneras. Para la sujeto, ha representado una opción de cambio, aun en el entendido de que para cambiar ha tenido que pasar por una vivencia de duelo.

El acceder al espacio público, al terreno de lo político, adquiere para la

s Véase Portugal, "Formación", 1989, p. 46. sujeto un lugar preponderante en las maneras de estructurar simbólicamente el futuro. "Hace su aparición explícita la acometividad, entendida en el sentido de valentía, osadía para emprender una cosa y arrostrar sus dificultades." Con cautela, decisión e inexperiencia, se muestra valiente en momentos decisivos y críticos de la situación, integrándose a la organización que se gesta en uno de sus espacios vitales de movimiento: su barrio.

La sujeto se reconoce como parte del Movimiento Civil de Damnificados 22 de Abril; ése es el espacio inicial, la causa primera. Sin embargo, la experiencia habla también de las connotaciones e implicaciones genéricas que se estructuran en los espacios políticos. No sólo tienen que ver con la mirada de los otros en relación con la sujeto, sino también con la propia manera de pensarse y resignificarse a partir de las experiencias acumuladas.

Hay un espíritu e ideal de lucha que se piensa y vive, pero existe el conflicto -inevitable- que trae consigo la asimilación de otras formas de entender el mundo. La renovación de la propia cultura produce estados conflictivos. El desprenderse, desarmarse, armarse y salir al mundo, coloca necesariamente en la cuerda floja. El conflicto se expresa en una tensión fundamental, entre las posibilidades de otra forma de autonombrarse y la inercia que provocan las representaciones tradicionales del ser mujer.

"Sólo podemos interpretar la diferencia entre los sexos[...]de un modo

${ }^{6}$ Hierro, Domesticación, 1990, p. 115. 


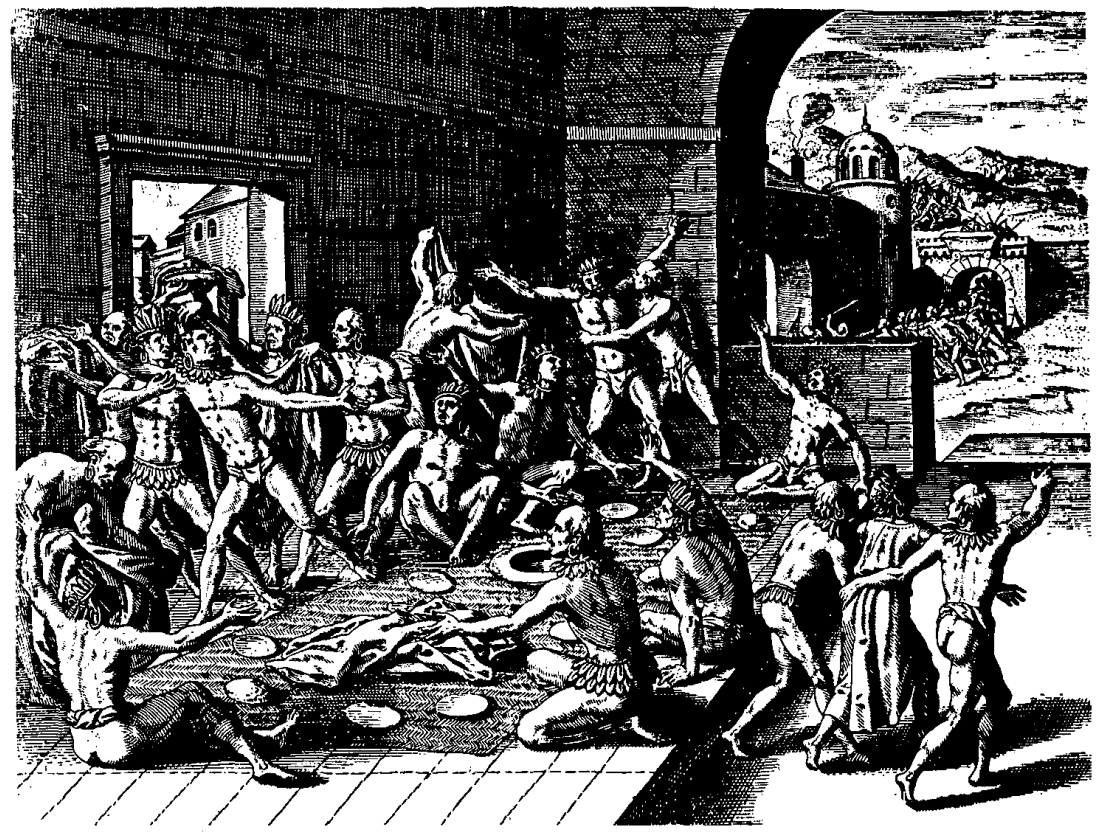

relacional y situacional, como parte de un sistema de relaciones asimétricas encarnado en las desigualdades de poder." En este sentido, la socialización de los individuos y las diferencias que se establecen en dicho proceso a partir de la diferencia sexual, describe la manera como se aprende la cultura, perpetuando los mundos opuestos y con ello las normas y valores específi-

\footnotetext{
${ }^{7}$ Hare y Marecek, Marcar, 1994, p. 234.
}

cos para hombres y mujeres. La cultura femenina y masculina se refuerzan a través del resultado de esa socialización diferencial provocando una desigualdad de oportunidades y posibilidades de desarrollo en la vida social, que se basa en la suposición de que -unas y otras- ocupan posiciones inferiores y superiores dentro de una estructura social jerárquica.

Creo que tenemos que insistir en que los sexos no deberían estar enlazados por medio de un acceso desigual 
a los recursos de la familia, la religión y la acción política -entre otros- proponiendo que unos tengan más valor que otros. El énfasis mayor tendría que estar en la construcción de representaciones que propicien la independencia y la libertad de género. La libertad entendida como "poder de decisión personal frente a las opciones vitales. Y la independencia como la asertividad del propio ser y quehacer." ${ }^{8}$ En este sentido, las prácticas comunicativas tienen un papel central en la formación de los individuos, pues en gran parte depende de ellas que sea posible comenzar a nombrar y vivir una cultura distinta que posibilite la vivencia de la diferencia en la igualdad.

Al final de este proceso de indagación las preguntas me asaltaron de nueva cuenta. ¿Y qué pasa con los hombres? ¿Cómo habitan ese cuerpo de hombre? ¿Será posible trabajar en la dirección de un cambio social sin considerar un trabajo más profundo con el hombre? Hoy intento responderlas. Cuando nos proponemos conocer otras formas de vida a través de la reconstrucción del saber, de cómo las personas dan sentido a la realidad y optamos para ello por el método de la historia de vida, como dice Renato Rosaldo "no existen atajos... No pode-

${ }^{8}$ Hierro, Domesticación, 1990, p. 115 mos usar simplemente la imaginación e inventar otros mundos culturales."

\section{BIBLIOGRAFIA}

-Bonnain, R. y Fanch Elegoet, "Mémoires de France: les archives orales pour quoi faire", Etbnologie Francaise, vol. 8, núm. 4, octubre-diciembre 1978, cit. por Morin, "Praxis", 1993.

-Hare Mustin, Rachel T. y Jeanne Marecek, Marcar la diferencia, Editorial Herder, Barcelona, 1994.

-Hierro, Graciela, De la domesticación a la educación de las mujeres, Editorial Torres Asociados, México, 1990.

-Lamas, Martha, $E l$ género: la construcción cultural de la diferencia sexual, Programa Universitario de Estudios de Género-UNAM, México, 1996.

-Mintz, Sidney, "The anthropological interview and the life history", The Oral History Review, 1979, pp. 18-26, cit. por Morin, "Praxis", 1993.

-Morin, Françoise, "Praxis antropológica e historia de vida" en Jorge Aceves (comp.), Historia oral, UAM/Instituto Mora, México, 1993 (Antologías Universitarias).

-Portugal, Ana María, "Formación y deformación; educación para la culpa" en $\mathrm{Mu}$ jeres e Iglesia. Sexualidad y aborto en América Latina, Catholics for a Free Choice/Ediciones Fontamara, USA/México, 1989.

-Rosaldo, Renato, Cultura y verdad. Nuevas propuestas de análisis social, CNCA/Grijalbo, México, 1991.

9 Rosaldo, Cultura, 1991, p. 35. 